\title{
Design and synthesis of triazole-chalcones.
}

Marina Goulart da Silva $(P G)^{1}$, Graziele Diniz da Silva (PG) ${ }^{1}$, Clebson L.Veber (PG) ${ }^{2}$, Andersson Barison $(P G)^{2}$, Gustavo H. R. Viana $(P Q)^{1}$, José Augusto F. P. Villar $(P Q)^{1 *}$.

${ }^{1}$ Laboratório de Síntese Orgânica - Universidade Federal de São João del-Rei - Campus Centro Oeste

Dona Lindu - Divinópolis/MG

${ }^{2}$ Laboratório de RMN - Universidade Federal do Paraná - Curitiba/PR

*zevillar@ufsj.edu.br

Keywords: chalcones, triazole and malaria.

\section{INTRODUCTION}

Chalcones are important natural products and can also be synthesized by aldol condensation reactions. These compounds have been reported to have a broad range biological activities such as antimalarial, antibacterial, antitumor, antioxidant, antihyperglycemic and anti-HIV ${ }^{1}$. Computational approach suggested that chalcones are potential plasmodial cysteine protease inhibitors ${ }^{2}$.

The triazole products are more than just passive linkers; they readily associate with biological targets, through hydrogen bonding and dipole interactions.

We describe the synthesis of new chalcones derivatives bearing a 1,2,3-triazole moiety as a new potential antimalarial agents.

\section{RESULTS AND DISCUSSION}

The proposed route is shown below:
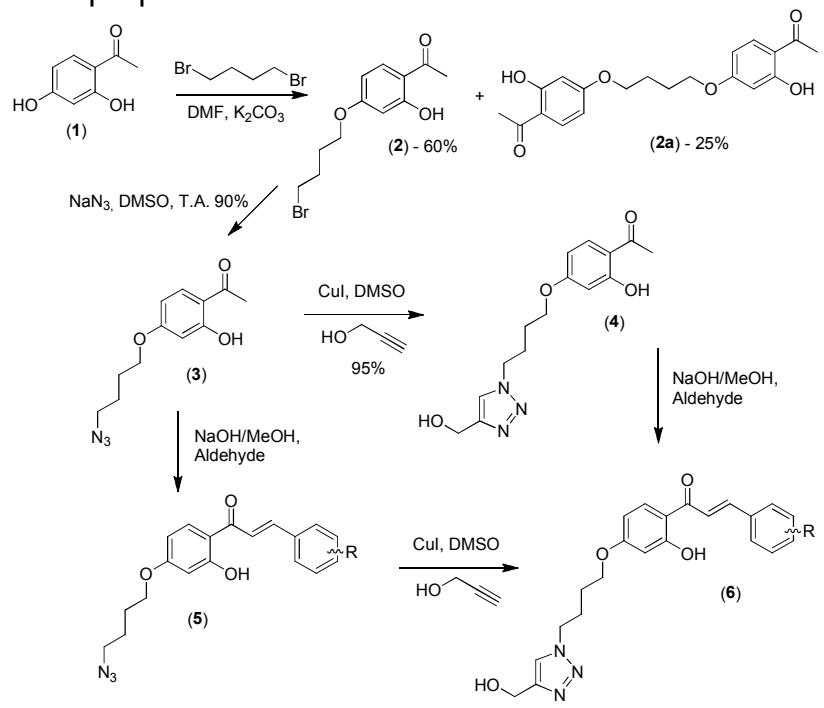

Figure 1. Route used for synthesis of novel chalcones derivatives carrying 1,2,3-triazole moiety.

Bromide (2) was easy prepared from (1) in $60 \%$ yield with formation of dimer $(\mathbf{2 a})$ and other products of alkylation in position 2. In next step bromide (2) was substituted with azide group. From this point two strategies were discussed. Compound (4) were obtained from (3) in high-yield (95\%) under 1,3- dipolar cycloaddition with propargyl alcohol using Cul in DMSO. Aldol condensation of (3) or (4) with different aromatic aldehydes give the corresponding chalcone derivatives (5) or (6) with yield ranges from moderate to good as shown in Table 1.

Table 1. Yields of aldol and cycloaddition reactions

\begin{tabular}{cccc}
\hline $\mathrm{R}$ & $(4) \rightarrow(6)$ & $(3) \rightarrow(5)$ & $(5) \rightarrow(6)$ \\
\hline $\mathrm{H}$ & $60 \%$ & $49 \%$ & $88 \%$ \\
$4-\mathrm{Cl}$ & $50 \%$ & $80 \%$ & $87 \%$ \\
$2,3-\mathrm{Cl}$ & $52 \%$ & $68 \%$ & $91 \%$ \\
$4-\mathrm{OMe}$ & $56 \%$ & $52 \%$ & $81 \%$ \\
$4-\mathrm{OEt}$ & $59 \%$ & $45 \%$ & $89 \%$ \\
$3-\mathrm{OMe}-4-$ & $40 \%$ & $77 \%$ & $83 \%$ \\
$\mathrm{OBu}$ & & - & - \\
$4-\mathrm{OH}$ & $44 \%$ & - & $83 \%$ \\
$3-\mathrm{OH}$ & $70 \%$ & $69 \%$ & \\
$4-\mathrm{OBu}$ & $48 \%$ & $62 \%$ & \\
$3-\mathrm{OBu}$ & $42 \%$ & & \\
\hline
\end{tabular}

\section{CONCLUSION}

The compounds were synthesized and successfully characterized. The chalcones derivatives are under evaluation for their antiplasmodial activity and soon will be possible to study the structure-activity relationship.

\section{ACKNOWLEDGEMENTS}

FAPEMIG, CAPES, CNPq, UFSJ e UFPR.

\section{REFERENCES}

1 Attar, S., O’Brien, Z, Alhaddad, H., Golden, M.L.,CalderónUrrea, A., Bioorganic \& Medicinal Chemistry 19 (2011) 20552073.

${ }^{2}$ Mishra,N.; Arora,P.; Kumar, B.; et al., European Journal of Medicinal Chemistry 2008, 48, 1530-1535. 